\title{
¿De Vagos a Ciudadanos \\ O de Ciudadanos a Vagos?: \\ EdUCACIÓN, CiUdADANÍA Y EXClUSIÓN EN \\ la Provincia de Cartagena, 1903-1920
}

\author{
Por: Rafael Acevedo Puello
}

Artículo Recibido:

Artículo Aceptado:

Del ciudadano podríamos decir lo que Tertuliano decía del cristiano: no nace se hace. Ser y sentirse ciudadano no es algo "natural", sino el resultado de un proceso cultural en la historia personal de cada uno y en la colectiva de una sociedad

Francois-Xavier Guerra ${ }^{1}$

\section{RESUMEN}

El propósito central de este articulo consiste en indagar acerca de los proyectos de ciudadanía y de no ciudadanos socializados en los códigos de instrucción pública y de policía en la Provincia de Cartagena, durante el periodo comprendido entre 1903-1920. Esto es, saber cuáles fueron los mecanismos formales e informales que, asociados a las escuelas y a las celebraciones patrias, hicieron posible la definición del ciudadano como un sujeto político con claras connotaciones católicas y productivas para su patria.

Palabras Claves: Educación, ciudadanía, escuela, vagancia, exclusión.

\begin{abstract}
The propose of this article is to inquire about the citizenships projetc and not citizenships in the codes of public instruccions and police in the province of Cartagena, during the period complised between 1903-1920. This is, to know, wich were formal and informal mechanisms that, associated to schools and natives celebration, made posible the definition of citizen like a politic subject with clear catholics connotations and profitables too for his nation.
\end{abstract}

Key Words: Education, citizenship, school, vagrancy, exclution. 


\section{Introducción}

$\square$ periodo comprendido entre 1903-1920, conocido en la historia colombiana como el de la hegemonía conservadora, estuvo caracterizado por la implementación de proyectos cívicos y pedagógicos destinados a rehacer los fundamentos de la patria y los lazos de unidad nacional. Luego de los enfrentamientos civiles decimonónicos, de la separación de Panamá y de las guerras civiles, las elites nacionales requerirían de la implementación de proyectos educativos para regenerar la identidad política de la nación como un cuerpo territorial, político y cultural. ${ }^{2}$ Se entendía que la instrucción pública era uno de los espacios más adecuados para dar cabida y hacer creer la idea de que se pertenecía a una misma naturaleza por poseer un pasado, unas costumbres, unas tradiciones, un lenguaje y una religión en común. El pasado era la independencia obtenida el 20 de julio de 1810 y el 7 de agosto de 1819, fechas estas emblemáticas de la construcción de cierta nacionalidad colombiana en la historiografía romántica, tradicional y positivista del siglo XIX; mientras las costumbres y las tradiciones tenían que ver con los legados y el proceso de creación, justificación y celebración de festividades centenarias en honor a esos acontecimientos memorables de la nación; y, finalmente, el idioma seguía siendo el español y la religión era la "Apostólica, Romana y Católica". ${ }^{3}$ En este sentido, los "saberes educativos" eran administrados con unos principios demagógicos y bien estatuidos al hacerse énfasis en aquellos valores políticos para dar la sensación no sólo de pertenecer a una misma nacionalidad, sino también para establecer una definición ontológica del ciudadano como un "hombre nacional o colombiano", 4 lo cual implicaba ser letrado y reconocerse como un individuo "patriótico", "católico", "culto" e "ilustrado". ${ }^{5}$ Así, la escuela se convertiría entonces en uno de los principales centros receptivos y difusores del pensamiento educativo acerca de la cultura política ciudadana del periodo objeto en este estudio.

Este discurso nacional sobre la ciudadanía encontraba entonces en las escuelas el espacio político más indicado para ser divulgado, comprendido e interiorizado por los próximos ciudadanos de la "imaginada nación" colombiana: los escolares. En este sentido, la formación del "hombre colombiano" era el resultado de los estereotipos religiosos, históricos y culturales bajo los cuales se pretendía dar la sensación de ser miembros de un mismo territorio nacional: la República de Colombia. ${ }^{6}$. Sin embargo, esta conceptualización del ciudadano moderno, lejos de incluir a todos los colombianos, terminaba siendo tan sólo un estatuto privilegiado, muy amplio ciertamente, pero privilegiado para aquellos sujetos que tenían la posibilidad de entrar a los colegios, donde podían eventualmente 
aprender a "leer y escribir", lo cual sumado a su buena posición económica podría ser un incentivo fundamental para participar y ser tenido en cuenta en los procesos democráticos del país. ${ }^{7}$ No obstante, la imposición de estos requisitos políticos, al no incluir a todos los habitantes de la sociedad colombiana, terminarían entrando en contradicción con los atributos universales (libertad, igualdad y fraternidad) del concepto del ciudadano propuesto por la filosofía política liberal para constituir las bases ideológicas de Naciones, Estados y Democracias, tanto en Europa como América Latina. ${ }^{8}$

De modo que la afirmación de aquellos requisitos para acceder al titulo de ciudadano excluía a un sinnúmero de habitantes circulantes, los no ciudadanos, quienes estaban por fuera del carácter privilegiado, estamental y normativo del "ciudadano republicano, patriótico, letrado y católico" definido por el gobierno nacional en reformas educativas como la de 1903. Los no letrados, los vagabundos, mendigos y marginales de todo tipo... que tropezaban con ésa figura de ciudadanía política quedaban entonces al margen de la "sociedad deseable". ${ }^{9}$ Y todavía más importante, al menos desde el gobierno nacional y del Departamento de Bolívar, durante el periodo comprendido de 1903 a 1920, no hubo ningún esfuerzo por implementar un proceso de educación para vincular a estos individuos a las escuelas y así garantizar el reconocimiento de la "calidad de nacional colombiano" o simplemente ciudadanos en ellos. De tal suerte que, como sucedió en la Provincia de Cartagena al iniciarse el siglo XX, la categoría de ciudadanía se tornaba excluyente y conservadora para unos grupos específicos que si podían acceder a la educación y a la única universidad del Departamento de Bolívar -como lo era la Universidad de Cartagena-, ese grupo indudablemente lo constituían las clases más pudientes de la ciudad: la elite local compuesta por altos dirigente político con mucha prestancia social y favorabilidad económica. ${ }^{10}$

En este articulo, por lo tanto, pretendemos llamar la atención y explicar cuáles eran los proyectos de definición y enseñanza de la ciudadanía y los no ciudadanos que aparecían en los códigos de instrucción pública y de policía en la Provincia de Cartagena, durante el periodo comprendido de 1903-1920. Esto es, saber cuáles fueron los mecanismos formales e informales que, asociados a las escuelas y a las celebraciones patrias, hicieron posible la definición del ciudadano como un sujeto político revestido de los rótulos privilegiados anunciados anteriormente. Así como también nos interesa analizar cómo esa conceptualización del "buen ciudadano" como un sujeto católico y educado terminaría excluyendo y legitimando como "indecentes" una serie de conductas populares, como los juegos de azar y ruleta, que parecían entrar dentro del orden de lo "deslegitimo" y lo "no formal" en el proyecto moderno de educación de los ciudadanos auspiciado por reformas 
y pensamientos educativos como la Ley Antonio José Uribe de 1903 y el Decreto Orgánico de Instrucción Publica 491 de 1904. Es, pues, la pretensión inicial de este trabajo hacer un breve repaso y cierta caracterización del "deber ser", los "atributos" y la "pedagogía cívica" en ese proceso de "formar" al ciudadano.

\section{El Concepto de Ciudadanía como Categoría Teórica e Histórica}

La categoría de ciudadanía como núcleo del discurso democrático y de la igualdad aparecería en el mundo occidental con las grandes transformaciones económicas, políticas, éticas y sociales, registradas entre 1750-1850. ${ }^{11}$ En especial, la construcción de un nuevo hombre, alejado de sus antiguos vínculos y deberes de vasallaje con respecto a su amo, fue una de las proclamas anunciadas por la Revolución Francesa. En efecto, la retórica del ciudadano llevaba implícita una concepción filosófica más liberal, igualitaria y fraterna, con relación al Ancien Régimen. El ciudadano surgía entonces como producto de unos derechos civiles, políticos y sociales adquiridos en su comunidad. Estos derechos lo hacían participe en los procesos democráticos, como el sufragio y la posibilidad de ocupar altos cargos públicos de carácter eclesiástico, militares y civiles; de ser miembro de una comunidad nacional, donde poseían y tenían la facultad de compartir el patrimonio social y cultural de su sociedad, así como también de expresare libremente; y de reclamar justicia cuando ésta lo ameritaba. En resumidas, el ciudadano estaba definido como un sujeto de derechos, ${ }^{12}$ y como tal, la noción moderna de ciudadanía reconocía en el ejercicio de la política su fundamento de ser.

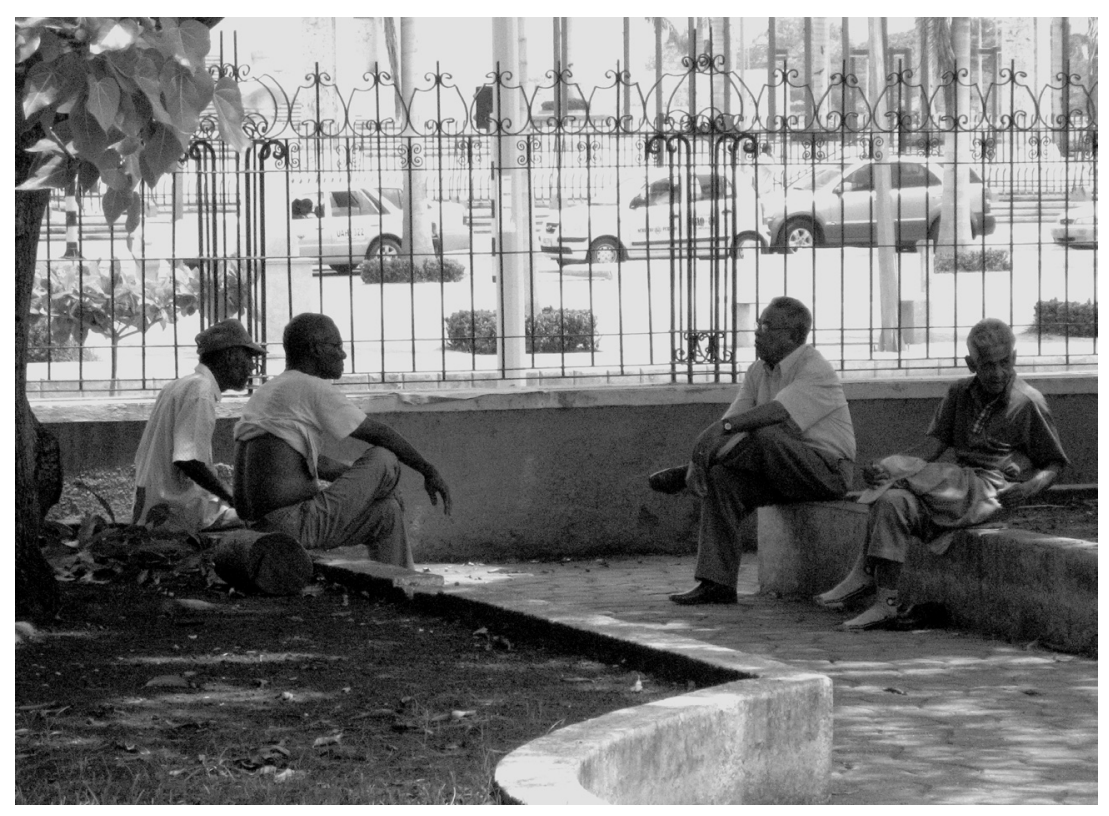

No obstante, esta definición teórica del ciudadano como un sujeto de derechos poseía ciertas limitaciones y su uso muchas veces divergía en los variopintos modelos de sociedad o de nación donde se ponía en práctica. Así por ejemplo: mientras que la utilización de este concepto serviría a los franceses para afirmar y legitimar el Estado Nacional frente al Ancien Régimen, concediéndole a todos los adultos clasificados como ciudadanos derechos y obligaciones para participar en el ejercicio de la 
soberanía y la representatividad moderna. ${ }^{13}$ En América Latina, por el contrario, la ciudadanía se revestía de unos privilegios corporativos y jerárquicos determinados por la propiedad, la notabilidad y la condición de vecindad alcanzada en un territorio determinado. ${ }^{14}$ Aunque, esto último no impedía que se experimentaran modelos de "ciudadanía alternativos" (o de "liberalismo popular" a modo de lo expresado por Antonio Anino) como sucedió en el México y el Brasil del siglo XIX. ${ }^{15}$

De modo que el proceso de construcción y definición política del ciudadano y su adverso, los no ciudadanos, surgía de las clasificaciones estatuidas sobre lo "prohibido" y lo "permitido", lo "legitimo" y lo "ilegitimo", lo "instituido" y lo "no instituido", lo "normal" y lo "anormal", los "acatos" y los "desacatos" emitidos por los gobiernos oficiales como el de los conservadores en Colombia durante 1903-1920. Dando como resultado estas asimetrías políticas la insinuación y socialización por un lado de un modelo ejemplar de ciudadanía y por otro, la conceptualización de un modelo de individuos "ociosos" o "vagos", quienes estarían dentro o por fuera de la lógica moderna de las identidades civiles dependiendo de su comportamiento, su educación y su identificación con las prácticas políticas de la nación o la localidad a la cual pertenecían. De allí que las escuelas, como sucedió en la Provincia de Cartagena a principios del siglo $\mathrm{XX}$, se vallan convirtiendo en los principales laboratorios de formación de la personalidad "notable", "católica", "ilustrada" y "culta" del ciudadano moderno. ${ }^{16}$ La ciudadanía, en fin, terminaba siendo una invención política legitimada por el sentido de la educación como espacio de "mejoramiento de las costumbres".

\section{¿Cómo Inventar al Ciudadano? : "Educar para Construir Buenos Ciudadanos", el Proyecto Educativo de 1903-1920}

\section{La Filosofía Educativa}

Eric J. Hobsbawm, historiador británico, en alguna ocasión sugería que las "identidades" son "tradiciones inventadas", entendiendo por estas últimas "(...) una serie de prácticas regidas habitualmente por unas normas aceptadas explícita o tácitamente y por un ritual de naturaleza simbólica, que tratan de inculcar a partir de su reiteración constante determinados valores y normas de comportamiento, lo que automáticamente implica un vinculo con el pasado".${ }^{17}$ Esta conceptualización del termino "identidades" se empleara en este trabajo para ilustrar como el proceso de formación de los ciudadanos, entre 1903 - 1920, estuvo caracterizado por la implementación de unas prácticas normativas representadas en la legislación escolar, 
a través de la cual generalmente se legitimaba la enseñanza de algunos rituales alusivos a la simbología y la religiosidad nacional, como la entonación del himno nacional, las izadas de banderas y las alabanzas a la divina providencia, todas las mañanas, para dar la sensación de ser "amantes" y "consecuentes" con el sentido de la nación colombiana como una "Belleza Patria" y una "unidad espiritual y cultural" en común. ${ }^{18}$ De tal manera que, en gran medida, la educación, o la entrada a una de las escuelas primarias o segundarias, bien podía constituirse en un primer paso para ser reconocido como ciudadanos dado las enseñanzas recibidas en ellas, dado la misión principal de aquella de enseñar a los escolares a "amar su patria" nacional.

De hecho, desde 1903 y hasta 1920, tras la emisión de la Reforma Orgánica de Instrucción Pública (1903) o Ley Antonio José Uribe, en todas las escuelas de la republica colombiana la educación nacional debía estar orientada hacia la enseñanza de la religión católica, las artes, la historia patria y los idiomas vivos que habilitan para el ejercicio político de la ciudadanía y la formación de hombres útiles. De allí que por aquella época de incertidumbres y separaciones políticas, como la de Panamá o el debate de si el mejor sistema político era centralista o federalista, ${ }^{19}$ hubo de tomarse la disposición en aquella reforma de construir cuatro niveles de enseñanza como focos principales del currículo escolar para fomentar la educación nacional y de esta manera dar la sensación de ser unos "ciudadanos colombianos", a saber eso niveles eran: la educación moral, la educación cívica, la educación intelectual y la educación física. ${ }^{20}$

La Educación Moral

La educación moral en ese sentido iba en consonancia con los proyectos religiosos, las normas de convivencia y las liturgias católicas que debían incorporarse como enseñanzas en el calendario de las escuelas públicas de la Provincia de Cartagena. Allí, por lo tanto, los maestros estaban en la obligación de enseñar a los niños los deberes para con Dios, para consigo mismo, para con sus padres y sus superiores, para con los semejantes y para con la patria. ${ }^{21}$ Por ello, muchos de los directores de escuelas decretaban a titulo propio como una norma: "la asistencia forzosa de los colegiales a misa todos los domingos" y la celebración de las mismas en sus recintos académicos, así como las invocaciones al Padre Nuestro, al Espíritu Santo y al Ave María mediante oraciones todas las mañanas antes de comenzar la jornada escolar. Y además, se programaban retiros espirituales, juegos, paseos y reuniones, para que de esta manera los escolares "purificaran su alma" y se habituaran al "don de la honestidad" que era indispensable para ser homenajeados 
en público por su "sabia disciplina". ${ }^{22}$ La vida escolar, vista así, podemos decir entonces que era la expresión de un tipo de cultura moral, sustentada esta en el cumplimiento y el amor a los preceptos bíblicos de la religión que actuaba en consonancia con el sistema de gobierno conservador: la católica.

En este sentido, en las escuelas de la Provincia de Cartagena, siguiendo las directrices de la Ley Antonio José Uribe, con la socialización de la educación moral se buscaba que "los niños adquieran en sus maneras, palabras, y acciones, hábitos de urbanidad, y los ejercitaran en la práctica de los deberes que el hombre bien educado tiene para la sociedad en que vive". ${ }^{23}$ Se entendía pues que había allí una definición del ciudadano como fruto de la educación y de su sumisión a las normas del Estado. Los niños educándose así debían dar muestras entonces de buen ejemplo y de respeto a la patria y por lo pronto, la ideología escolar esperaría convertirlos en buenos ciudadanos. ${ }^{24}$ Pero, desde otra perspectiva más critica y menos apologética de la historia de la educación, se entendía también que la educación tenía como propósito limitar el espíritu critico de los estudiantes al prohibirles a estos posiciones reprochas frente a ese tipo de pedagogía católica. De modo que ser ciudadano o formarse como ciudadano parecía al mismo tiempo ser un "guardián prudente" y "poco critico" del proyecto nacional de "ciudadanías obedientes", auspiciadas por la concepción católica del ciudadano como un sujeto tolerante hasta con las parábolas políticas de su gobierno nacional. Tanto era así que, en el afán por hacer palpable las creencias religiosas como fuente de los buenos comportamientos del ciudadano, en el Decreto Orgánico de Instrucción Pública 491 de 1904, a las escuelas se le exigía que:

100-Articulo 49. Principalmente por un buen régimen de la escuela, el institutor trabajará por la cultura moral. La dignidad que imprimirá á todos sus actos y en su lenguaje, su respeto por la justicia, su afecto sincero por la infancia, le permitirán establecer una sabia disciplina, y le asegurarán la obediencia, el respeto y el amor de sus discípulos. Colocado así en las condiciones de un buen padre de familia, procurara que sus enseñanzas sean como las del hogar doméstico, llenas de sencillez, de bondad y de virtud. Para ello aprovechará todos los actos en la escuela como las recreaciones, los juegos, los paseos, los mil incidentes de la vida escolar, para iluminar la conciencia de sus discípulos, á fin de desarrollar las buenas inclinaciones y de ejercitar y cultivar la voluntad en sus aplicaciones al bien. ${ }^{25}$

De tal manera que con el sentido moral de la educación se intentaba pensar, inventar y hacer creer entre los estudiantes, próximos ciudadanos, la idea de que aclamando a Dios cultivaban el bien y contribuían al engrandecimiento espiritual de su patria. Ya que, como se rezaba en una noticia oficial en la Provincia de Cartagena en 1903, la dirección que se da a la educación depende de la idea que 
aquellos se formen del hombre perfecto, cuanto más nos aproximamos; por medio de sistemas prácticos, al verdadero ideal que no puede ser otro que el que nos dejo Jesús, el gran maestro de la humanidad, tanto más nos alejamos del estado de relativo atraso en que nos encontramos hoy. ${ }^{26}$ Así, la enseñanza de lo religioso debía constituirse en un elemento vital para garantizar el progreso de la republica, aun cuando la educación intelectual debía responder también por la formación útil del ciudadano como un "hombre productivo o trabajador".

La Educación Intelectual

En ese orden de ideas, la invención del ciudadano estaba articulada a la idea de construir un hombre productivo y como tal, se hacia necesario adiestrar a los estudiantes entorno a un tipo de educación intelectual, cuya característica principal de esta era:“(...) habilitarlo para el ejercicio de la ciudadanía y prepararlo para la agricultura, la industria fabril y el comercio" ${ }^{27}$ En efecto, los colegiales debían ser útiles para el desarrollo de su sociedad y por ello, desde los espacios escolares, se le debía enseñar a trabajar. De tal modo que la invención del "buen ciudadano" no sólo se refería a ideales cristianos asociados a pautas de comportamientos, sino, asimismo, a la incorporación de ideas de trabajo y de productividad recibidas en sus espacios de formación académica y profesional, pues un "buen ciudadano" ante todo debía ser un "sujeto productivo".

Esta educación en ese sentido estaba orientada hacia la enseñanza de las facultades productivas del futuro ciudadano, quien debía prepararse desde la escuela para su vida profesional, lo cual, de alguna u otra manera, explicaba la existencia de colegios con un énfasis en la ilustración técnica y las bellas artes en la Provincia de Cartagena. Como el Colegio de Nuestra Señora del Carmen, El Colegio San Pedro Claver, El Colegio de Heredia, el Colegio Martínez Olier, el Colegio Fernández Madrid, entre otras instituciones públicas y privadas, en donde se les enseñaba a los estudiantes a fabricar sombreros, pellones y alpargatas, bobinas y cachuchas, hamacas y tejidos, entre otras manufacturas propias del conocimiento agrícola manual, en sus horarios normales de clases. Al tiempo que se vendían estas artesanías fabricadas por ellos y sus fondos se destinaban al mejoramiento de orfelinatos y hospitales y al incremento de los fondos comunes departamentales, de modo que los escolares desde sus espacios educativos ya se preparaban profesionalmente y aportaban con sus trabajos al engrandecimiento, el bienestar y la beneficencia publica de su patria política. ${ }^{28}$ De allí que la identidad del ciudadano si bien respondía a unos intereses morales de carácter nacional, cierto es el hecho de que esta también iba a tono con las demandas de "trabajadores 
útiles" por parte de ciudades en continuo progreso comercial, fabril e industrial como la Provincia de Cartagena. ${ }^{29}$

En consecuencia, la invención del ciudadano respondía a una simbología, la preparación y el culto al progreso; a unos valores, ser útil y productivo a la sociedad y una norma, ser profesionales para acreditar el titulo de ciudadanía. El ciudadano arraigado a la enseñanza de los valores cristianos en sus escuelas no desentonaba para nada con el sentido de su formación como un profesional, un trabajador y un sujeto productivo para su provincia, a fin de que adquiriendo esas destrezas académicas y laborales fuera reconocido como un "ciudadano digno" por contribuir con su fuerza física y emocional al engrandecimiento de la patria.

\section{La Educación Cívica}

Por ello, además de la educación moral e intelectual, la afirmación de la educación cívica debía servir para ejemplificar en gradados, lecciones y representaciones de personajes eminentes del pasado, como el héroe nacional Simón Bolívar, la imagen del ciudadano como sujeto amante de los principios políticos y morales de su patria. Dicho de otro modo, la educación cívica acude al pasado para socializar modelos de conductas religiosas, patrióticas y cívicas, ${ }^{30}$ de allí que en ella recayera fundamentalmente la organización de festividades centenarias como la del 20 de julio de 1910, el 11 de noviembre de 1911 y el 7 de agosto de 1919. Así, por ejemplo, en vísperas de la conmemoración de la primera festividad centenaria de la independencia de la Provincia de Cartagena en 1911, desde las escuelas se organizaron concursos, cartillas, pinturas y representaciones teatrales intercolegiales entorno a tal acontecimiento para dar a entender cuál fue la importancia política de esos ciudadanos del pasado, ${ }^{31}$ destacándose como importante en ello el sacrificio de los próceres (García de Toledo, Rodríguez Torices, Díaz Granados, Castillo Rada, Portocarrero, Amador, Ribón, Aguiano, Stuard y Ayos) por el progreso de la patria. Por ello, en los aproximadamente 20 actos públicos en los que participaron los estudiantes en la festividad centenaria de 1911, por lo general, regaban flores y cantaban el himno nacional al lado de las estatuas de esas figuras políticas y de ciudadanía como una forma esto de valorar, agradecer e identificarse con la idea del "amor patrio" como expresión ciudadana. $^{32}$

La instrucción cívica, entonces, a diferencia de las otras, ya no es sólo el lugar de la enseñanza, sino, además, el escenario de la representación de lo aprendido 
en las clases. Esto último, por ejemplo, se notaría en las exposiciones que debían hacer los escolares en honor a las "bellezas de la Patria", sobre sus fastos gloriosos, sobre los hombres que la han ilustrado, con el fin de suscitar en ellos(los educandos) el entusiasmo patriótico ${ }^{\text {af33 }}$. Esto explica porque todos los días los colegiales debían ensayar el himno nacional, enarbolar la bandera y hacer juramentos delante de esta simbología. A la vez, los estudiantes no podían iniciar sus actividades sin hacer alusión a los rituales cristianos y, de igual manera, no podían terminar su jornada escolar sin haber recordado a la ciudad dentro de la simbología nacional. ${ }^{34}$

En resumidas cuentas, para ser ciudadano, además de ser un hombre culto e intelectual, se requería poner en práctica lo aprendido. Esto a su vez era una forma de mostrar los lazos de la nación, el pasado, las normas, la simbología y el sentido de patria en común, tan debilitados estos con la perdida de Panamá y la guerra de los mil días. ${ }^{35}$ La tarea en ese sentido era mostrar de manera "virtual" la solidez de la nación y las urbes que la componían. De allí que la ciudadanía resultara ser una invención política, caracterizada ésta por dar cierta sensación de orden y progreso.

\section{La Educación Física}

Finalmente, se instituyó como uno de los niveles de la educación nacional la educación física que por un lado era una forma de recrear a los escolares pero por otro, era un mecanismo de vigilancia y de control sobre los modales de comportamiento de los futuros ciudadanos. Por ello, en las escuelas se insistía en la definición y enseñanza de la gimnasia como sinónimo de preparación militar, pues a través de esta ilustración los estudiantes debían aprender ciertos hábitos como marchar y vestirse correctamente, a asearse y a guardar posición natural y correcta durante las lecciones. Este adiestramiento militar, a la vez, tenía un significado político: "la corrección de los malos hábitos de los estudiantes y su preparación para las conmemoraciones de la patria", ${ }^{36}$ debido a que en este tipo de celebraciones los alumnos debían engalanar con su presencia los actos solemnes de la patria marchando y cantando correctamente el himno nacional al lado de las estatuas de los próceres nacionales y locales de la independencia cartagenera. Por lo que había entonces que adiéstralos a ellos bajo una "rígida disciplina" educativa, la cual iba desde el control del cuerpo hasta el aprendizaje de los conocimientos útiles, técnicos e históricos. Esto último podemos constatarlo, por ejemplo, en uno de los reglamentos de los colegios más tradicionales de Cartagena, el Colegio Fernández Baena, fundado en 1933, donde aparecía la siguiente disposición sobre 
la instrucción de la gimnasia:

Para el desarrollo físico del alumno, tiene el colegio un gimnasio. La clase de gimnasia está bajo la dirección de un técnico, para evitar que sus resultados sean contra producentes. Combinada con la clase de gimnasia se da la de milicia, que a la par que desarrolla, disciplina militarmente al alumno, futuro soldado de la patria. ${ }^{37}$

Desde ese punto de vista, las escuelas no eran solamente el escenario en donde debían ponerse en escena la pedagogía cívica y moralizante de la época, sino, asimismo, el lugar de exhibición y representación de la figura del ciudadano como un sujeto "amante de las leyes" de su patria, lo cual quedaba ejemplificado en la figura del soldado, "hombre capaz de sacrificar su vida por la patria", como el prototipo a imitar por parte de los futuros ciudadanos formados en los colegios de la básica primaria y segundaria en la Provincia de Cartagena de Indias. Esta exhibición y representación se daba a partir de la educación cívica y de las prácticas corporales desarrolladas con la educación física. De manera que el ciudadano debía ser un sujeto activo en los actos sagrados y solemnes preparados por la dirigencia escolar para engalanar las conmemoraciones patrias, para de esta manera mostrar su "amor patriótico" por el territorio donde había nacido. En resumidas, la invención del ciudadano era una retórica y una practica social vivida al interior y al exterior de las instituciones educativas.

Por ello, en muchos catecismos de historia patria, como el escrito por Jesús Maria Henao y Gerardo Arrubla en 1910, quizás con el animo de dotar a los estudiantes de cierta identidad nacional, se decía que: "es buen ciudadano el que conoce, ama y cumple sus deberes; honra la santidad de la Religión y del hogar; respeta y obedece á la legitima autoridad; quiere más el bien público que el suyo propio, y aspira siempre al honor y al engrandecimiento de la patria". ${ }^{38}$ Dicho de otro modo, "ser y hacerse ciudadano" significaba también "ser y hacerse un ejemplo de vida humana".

De Ciudadanos a Vagos o de Vagos a Ciudadanos: La Invención de los Civiles en los Códices de Policía.

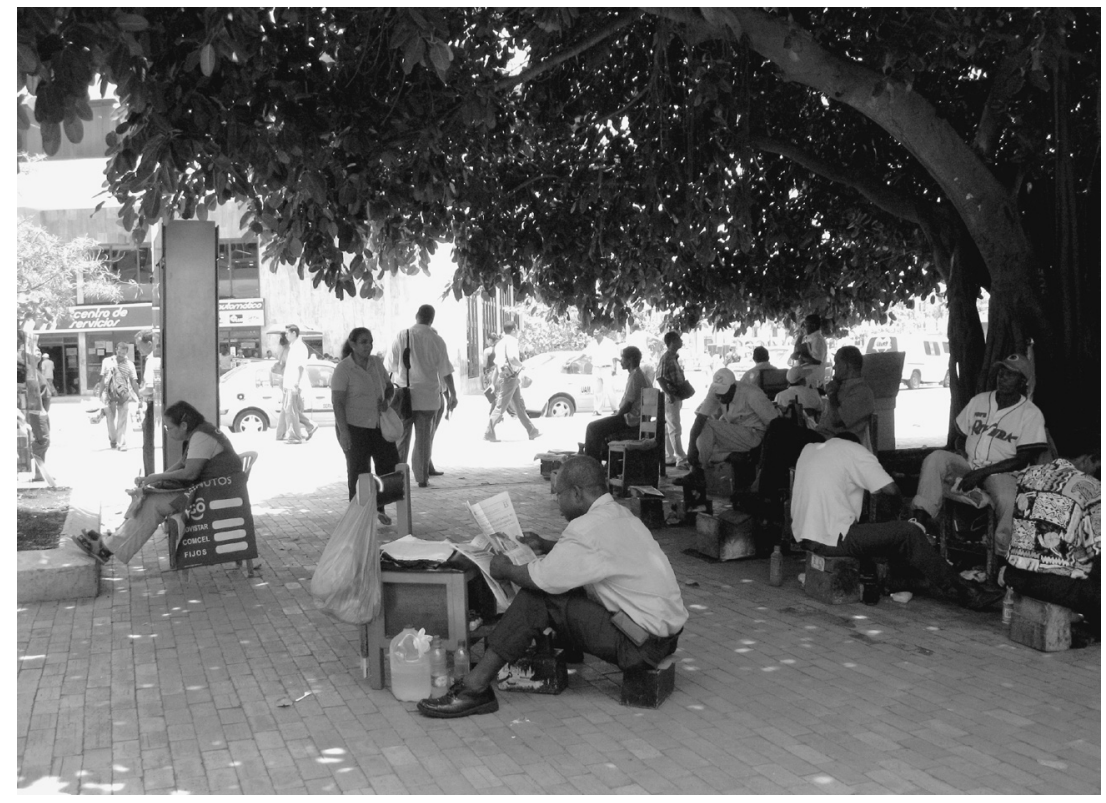


El infortunio de no pertenecer a una escuela o a una profesión: La ciudadanía a la inversa para los hombres

Sin embargo, las representaciones corrientes en torno al ciudadano de la nación y de sus urbes principales como la Provincia de Cartagena, lejos de ser disolutas, iban al mismo tiempo fabricando el cuerpo de los no ciudadanos, a quienes muchas veces se les registró en las constituciones y códigos de policía como "vagos", "holgazanes", "ociosos", "viciosos" y en fin: "personas de malas conductas" por no encarnar el prototipo del ciudadano letrado, productivo y obediente a las leyes de la patria. ${ }^{39}$ Así, frente a la imagen del ciudadano instruido, también, se construía una imagen "pecaminosa" e "inmoral" sobre los sujetos varones desprovistos de educación. A éstos últimos, por lo tanto, los excluían de derechos políticos como la participación electoral por no "saber leer y escribir", por su nula o poca posesión de rentas, o en su efecto contrario, por su favorable posición económica pero con una vida y "conciencia desarreglada"..$^{40}$ De esta manera, el estereotipo del ciudadano como un sujeto de derechos quedaba restringida a una sola definición: el hombre educado.

Este sujeto educado, a su vez, fácilmente, podía pasar de ciudadano a vago, así como también, a la inversa, podía transitar de vago a ciudadano. En efecto, en los códices de policía estaba estatuido que los hombres siempre y cuando accedieran a la educación de la republica lograrían su reconocimiento como miembros de ella. Pero, de igual manera, aquellos que fuesen expulsados reiterativa y definitivamente de una institución, llámese escuelas, fábricas, iglesias o de otros establecimientos públicos, ingresaban a las filas de vagos y holgazanes de la nación y las ciudades que la componían. ${ }^{41}$ En la Provincia de Cartagena, por ejemplo, los inspectores de policía fueron los encargados de definir el conjunto de conductas permitidas y prohibidas tanto para hombres como mujeres, esas conductas iban desde el desacato a las autoridades hasta la perdida del tiempo en las casas de juegos, las reiteradas idas a las cantinas o el estarse mucho tiempo sentado en las esquinas de una calle (ver el cuadro numero 1). En consecuencia, el vago personificaba la lujuria y la vida dispendiosa, el revés del ciudadano ejemplar, en aquel tiempo, cuando la lógica de la ciudadanía y el mercado de trabajo demandaban de un trabajador entregado de manera constante, rutinaria y eficaz a sus labores diarias. Así pues, la vagancia constituía el envés de la identidad política y nacional del nuevo hombre fabricado por las escuelas. ${ }^{42}$ 


\section{Cuadro 1}

Prácticas Permitidas y Prohibidas en la Provincia de Cartagena a Finales del Siglo XIX y Principios del XX

\begin{tabular}{|c|c|c|c|}
\hline No. & $\begin{array}{l}\text { CONDUCTAS DE } \\
\text { VAGANCIA }\end{array}$ & JUEGOS PROHIBIDOS & $\begin{array}{l}\text { NORMAS Y JUEGOS } \\
\text { PERMITIDOS }\end{array}$ \\
\hline 1 & $\begin{array}{l}\text { Las personas que se } \\
\text { alimentan o subsisten } \\
\text { con dineros ilícitos. }\end{array}$ & $\begin{array}{l}\text { Juegos de suerte y azar: } \\
\text { ruleta, el macondo, } \\
\text { ruedas de fortuna, la } \\
\text { bragueta, el boliche, las } \\
\text { barajas, entre otros. }\end{array}$ & $\begin{array}{l}\text { Rifas, loterías, carreras } \\
\text { de caballos y los } \\
\text { juegos de gallos con su } \\
\text { respectivo permiso por } \\
\text { parte de las autoridades. }\end{array}$ \\
\hline 2 & $\begin{array}{l}\text { Los hombres que } \\
\text { establezcan relaciones } \\
\text { constantes con personas } \\
\text { ociosas, viciosas y de } \\
\text { malas costumbres. }\end{array}$ & $\begin{array}{l}\text { Los juegos relacionados } \\
\text { con apuestas de dinero. }\end{array}$ & $\begin{array}{l}\text { Las diversiones } \\
\text { encaminadas hacia una } \\
\text { obra de beneficencia. }\end{array}$ \\
\hline 3 & $\begin{array}{l}\text { Los hombres y mujeres } \\
\text { escandalosos y sin } \\
\text { educación. }\end{array}$ & $\begin{array}{l}\text { La asistencia de niños } \\
\text { o personas en estado } \\
\text { de beodez a las casas de } \\
\text { juegos permitidos. }\end{array}$ & $\begin{array}{l}\text { Los juegos en clubes } \\
\text { que paguen el impuesto } \\
\text { anual. }\end{array}$ \\
\hline 4 & $\begin{array}{l}\text { Los menores adultos, } \\
\text { sirvientes domésticos o } \\
\text { jornaleros entregados a } \\
\text { los juegos prohibidos }\end{array}$ & $\begin{array}{l}\text { El establecimiento y } \\
\text { desarrollo de } \\
\text { diversiones publicas } \\
\text { sin permiso de las } \\
\text { autoridades. }\end{array}$ & $\begin{array}{l}\text { Las casas de juegos } \\
\text { prohibidos que no } \\
\text { dejaran entrar a los } \\
\text { menores, jornaleros o } \\
\text { aprendices. }\end{array}$ \\
\hline 5 & Las mujeres publicas & $\begin{array}{l}\text { Las diversiones en horas } \\
\text { de clase o trabajo. }\end{array}$ & $\begin{array}{l}\text { Los juegos se permiten } \\
\text { sólo en recintos } \\
\text { privados. }\end{array}$ \\
\hline 6 & $\begin{array}{l}\text { Los oficiales, jornaleros, } \\
\text { aprendices y sirvientes } \\
\text { con un precario sueldo. }\end{array}$ & $\begin{array}{l}\text { Los juegos contrarios a la } \\
\text { moral y dignidad católica }\end{array}$ & $\begin{array}{l}\text { A los jugadores no se les } \\
\text { pueden pedir gabelas o } \\
\text { tributos. }\end{array}$ \\
\hline 7 & $\begin{array}{l}\text { Los estudiantes que no } \\
\text { asistan a clases y aquellos } \\
\text { que sean expulsados de } \\
\text { los colegios. }\end{array}$ & $\begin{array}{l}\text { Los juegos con } \\
\text { manifestación de golpes. }\end{array}$ & $\begin{array}{l}\text { Prohibido las apuestas } \\
\text { en dinero o especie. }\end{array}$ \\
\hline 8 & $\begin{array}{l}\text { Los que mendigan o } \\
\text { irrespeten a la policía }\end{array}$ & $\begin{array}{l}\text { La venta de licor o } \\
\text { sustancia alucinógena } \\
\text { en las casas de juegos } \\
\text { permitidos }\end{array}$ & $\begin{array}{l}\text { Las galleras sólo } \\
\text { funcionaran en días } \\
\text { feriados de las } 7 \text { de la } \\
\text { mañana a las } 6 \text { de la } \\
\text { tarde }\end{array}$ \\
\hline 9 & $\begin{array}{l}\text { Los trabajadores } \\
\text { independientes, sin } \\
\text { puesto de trabajo fijo. }\end{array}$ & $\begin{array}{l}\text { Los juegos con } \\
\text { manifestación de injuria } \\
\text { verbal. }\end{array}$ & $\begin{array}{l}\text { Las casa de } \\
\text { juegos permitidos } \\
\text { serán revisadas } \\
\text { periódicamente por la } \\
\text { policía }\end{array}$ \\
\hline 10 & $\begin{array}{l}\text { Los embriagados y } \\
\text { ladrones. }\end{array}$ & $\begin{array}{l}\text { El desarrollo reiterativo } \\
\text { de rifas, loterías, entre } \\
\text { otras apuestas. }\end{array}$ & $\begin{array}{l}\text { Prohibido cualquier } \\
\text { tipo de escándalos en } \\
\text { las casas de juegos } \\
\text { permitidos. }\end{array}$ \\
\hline 11 & $\begin{array}{l}\text { Los condenados por ir } \\
\text { a los juegos prohibidos } \\
\text { o por abuso de juegos } \\
\text { permitidos. }\end{array}$ & $\begin{array}{l}\text { Las diversiones públicas } \\
\text { o populares en las } \\
\text { conmemoraciones } \\
\text { religiosas o patrias }\end{array}$ & $\begin{array}{l}\text { Se cerrara el } \\
\text { establecimiento cuando } \\
\text { estos falten a la norma }\end{array}$ \\
\hline
\end{tabular}

Fuente: DÁVILA FLOREZ, MANUEL (1903). Código de policía del departamento de Bolívar con las modificaciones introducidas por las ordenanzas posteriores á la 54 de 1892. Cartagena, Tipografía de Vapor de Araujo L., pp. 209-213. De igual manera ver: CALVO, RAFAEL (1925) Código de policía del Departamento de Bolívar. Cartagena, Ed. Departamental, págs. 209-232; CALVO, RAFAEL (1930) Código de policía del Departamento de Bolívar. Cartagena, Imprenta Departamental, págs.. 107-135. 
Como se observa en la anterior gráfica, los códices de policía servían como instrumento de socialización del concepto del vago, definido este como el hombre propenso a la vida disipada y el deterioro de la imagen del cristiano, el trabajador, el patriota y el hombre republicano como prototipo del buen ciudadano. Todas las conductas señaladas en el cuadro construían el adverso de los valores políticos enseñados en las escuelas. La identidad del ciudadano notable, así, era el lugar desde donde se inventaba también al no ciudadano. ${ }^{43}$ Tanto era así que, proporcionalmente a la vagancia, los Inspectores de Policía castigaban a esos individuos por fuera de la "civilidad" vinculándolos a formas de trabajos útiles para la sociedad, es decir, la imagen del ciudadano como sujeto productivo era la estrategia para contradecir el opuesto del honorable ciudadano. ${ }^{44}$ De esta manera, el vago consolidaba la posibilidad de algún día llegar a adquirir cierto reconocimiento cívico, pero lo más común era pasar de ciudadanos a vagos en una sociedad marcada por la exclusión, la nominalización y el no reconocimiento político de aquellos individuos por fuera de la lógica educativa del ciudadano. Así, por ejemplo, en el diario El Porvenir, en 1911, el paso de ciudadanos en formación a vagos, por la "irreverencia" de algunos estudiantes entregados a los vicios de la calle y sus malas conductas, era condenado bajo el calificativo de "suciesa moral" en una noticia pública de la siguiente forma:

Nos referimos hace pocos días a la suciesa material que invade este parque, y hoy tenemos que referirnos a la suciesa moral de que hacen gala algunos jovenzuelos que lo frecuentan - digna compañera la una suciesa de la otra. Estos mozos de levita gastan un lenguaje de taberna y llevan su vulgaridad al extremo de permitirse dirigir frases atrevidas a las señoritas que al dirigirse a la escuela Normal tienen que pasar por aquellos sitios. Por allí no hay un agente de policía, y si lo hay no sabe cumplir su deber. ${ }^{45}$

De la anterior denuncia llama la atención como terminaba haciendo un reclamo en torno a la presencia de la policía, pues esto nos da a entender que ellos (los policías) tenían cierta inherencia sobre el control del "culto publico" en las escuelas, y más aún, sobre los próximos ciudadanos. ${ }^{46}$ Estas autoridades, en efecto, eran las encargadas de vigilar a los futuros civiles por fuera de sus horarios de clases. Mientras que a los educandos que siendo hijos de familia y pupilos no estén matriculados en las escuelas, publica o privada, de artes o de oficios, recaía entonces la condena del vago en dicha legislación policiva. Pero, asimismo, esta censura penetraba a los colegiales renuentes al cumplimiento de sus actividades educativas, los que no asistían a clases, los que fuesen expulsados, los indisciplinados y los que cometieran desordenes públicos de cualquier naturaleza que quedaban del mismo modo bajo la vigilancia de la policia. ${ }^{47}$ De modo que el concepto y la imagen de los no ciudadanos no era ajena ni mucho menos ausentes a la filosofía escolar del 
periodo, frente a esa imagen no obstante no dejaron de luchar los inspectores de Instrucción Pública y la dirigencia de la época.

Así pues, la invención de los no ciudadanos o vagos se hacia con las mismas estrategias políticas conforme a las cuales se formaba a los ciudadanos, es decir, con unas normas, la legislación policiva y los castigos escolares; con unos rituales, las crónicas y reportajes censurables en torno a los no ciudadanos como anticatólicos y poco patrióticos; y con un pasado, la tradición religiosa e hispana colonial retomada en la republica. De manera que este juego de invenciones entre lo prohibido y lo permitido era el reflejo de una sociedad en busca de su identidad perdida, de una nación cuyas clases dirigentes estaban preocupadas por reafirmar: el espíritu católico, las relaciones con la iglesia, con la colonia y con la patria independiente, a fin de restablecer los lazos de unidad nacional debilitados por las guerras, las separaciones y la fragmentación territorial de la misma.

\section{La Educación de la Mujer}

Tanto era así que, además de la formación cívica de los hombres, la educación de las mujeres constituía un caso sui géneris, puesto que por un lado éstas se educaban con los mismos principios políticos del ciudadano pero por otro lado, ellas no llegarían a ser reconocidas como ciudadanas ni de la nación ni de su ciudad. No obstante, no hay razones para decir que el sexo femenino no hacia parte del sistema educativo cartagenero, pues la presencia de éstas en las escuelas era visible, e inclusive, hasta existían y entraban a instituciones netamente femeninas como el Colegio de Nuestra Señora del Carmen o las Escuelas Normales de niñas que sesionaban en la Provincia de Cartagena. En estas instituciones, por ejemplo, las mujeres recibían clases sobre bordados, fabricación de tejidos, manufacturas, así como también sobre conocimientos patrios, vocación religiosa y cátedras de urbanidad y buenos modales, lo cual comprobaba el carácter técnico, clásico e histórico de sus actividades escolares. Las mujeres, en ultimas, también, se preparaban para la vida profesional y los deberes para con ellas mismas, con las autoridades, con su familia, con Dios y con la Patria política a la cual pertenecían. ${ }^{48}$

La educación para las mujeres significaba, entonces, una oportunidad para salir del mundo domestico y para instalarse en la esfera profesional. Una vez instaladas allí tenían la oportunidad de ocupar cargos públicos importantes como ser institutora de una academia o de una escuela, a aspirar a ganarse la vida con sus propias manos. Esto era un reto al paradigma patriarcalista al cual habían estado 
subyugadas por mucho tiempo. ${ }^{49}$ Desde ese punto de vista, el sexo femenino asumía la educación, no como un requisito para acceder a derechos políticos como la ciudadanía, sino, más bien, como un reto para autosuperarse y para depender de ellas mimas. Sin embargo, para las clases dirigentes la educación de aquellas constituía la oportunidad para incrementar la mano de obra femenina, de allí el interés de los Inspectores de Instrucción Pública por vincularlas a las escuelas. ${ }^{50}$ La educación femenina, vista así, era una forma de construir el cuerpo del "sujeto trabajador", como era esta también la lógica para la educación de los hombres.

Tanto era así que la mujer trabajadora tenía también su antítesis: las prostitutas o las mujeres de la vida licenciosa. En los códigos de policía, de hecho, había varias disposiciones donde se definía a las meretrices no solo como aquellas dedicadas a la satisfacción de los placeres sexuales por negocio, sino, asimismo, como la mujer incapaz de ganarse los alimentos de modo lícito. ${ }^{51}$ De modo que este tipo de mujeres eran objeto de exclusiones y vejaciones por parte de las autoridades civiles. Se les obligaba a ellas, por ejemplo, a vivir en los márgenes de la ciudad, a someterse a un control de sanidad semanal y a estar lo más distante posible de los centros de control moral: planteles de educación, iglesias, casas de beneficencia, hospitales, monasterios, y demás instituciones públicas. ${ }^{52}$ Así, la mujer no trabajadora era propensa a ser considerada holgazana y proclive a la "vida alegre". Como tal, la educación debía ser el mecanismo de transmisión de las buenas formas de comportamiento, de la moral pública que debían poseer. Tal como los hombres, las mujeres eran objeto entonces de una invención política, esa invención tenia que ver con su consideración como un ser culto, letrado y profesional. En lo único que diferenciaban con el sexo masculino era que ellas, el sexo femenino, muy a pesar de "saber leer y escribir", no podían concurrir a las jornadas electorales

\section{Conclusión}

Así pues, los proyectos de construcción de ciudadanía auspiciados por las escuelas terminaban excluyendo y calificando como "vagos" a todos aquellos individuos que no podían entra a los colegios, por estar ellos propensos a la vida disipada. En la Provincia de Cartagena entre 1903-1920, entonces, "ser y sentirse" ciudadano era hacerse en las escuelas, es decir, acceder a esos espacios de formación que, además de no contar con las adecuadas condiciones para la buena educación y para permitir el acceso de la población a las mismas, se convertían también en el espacio político por excelencia para dotar a los ciudadanos de un a identidad nacional, como era éste el objetivo perseguido en la reglamentación de educación publica para estar a la "altura de los tiempos". 


\section{BIBLIOGRAFÍA}

BENDIX, Reinhard. (1980). Estado Nacional y Ciudadanía. Amorrortu Editores, Buenos Aires, 285pp.

FURET, Francois. (1980). Pensar la revolución francesa. Ediciones Petrel. Madrid.

FONTANA, Joseph .(2003). "Estado, nación e identidad en América Latina". En: ¿Para qué sirve la historia en un tiempo de crisis? Bogotá, Ediciones Pensamiento Crítico / Colección Mundo sin Fronteras. Madrid.

HELG, Aline. (1987). La educación en Colombia 1918-1957: una historia social, económica y política. Fondo Editorial CEREC. Bogotá.

HERRERA, Marta. (2001). Debates sobre raza, nación y educación: ihacia la construcción de un < < hombre nacional $>>$ ? . En: Marta HERRERA Y Carlos JILMAR DÍAZ (Compiladores). Educación y cultura política: una mirada multidisciplinaria. Universidad Pedagógica Nacional. Bogotá.

HOBABAWM, Eric y Terence, RANGER. (1983). The invention of tradition. Cambridge University Press. Norteamérica.

JARAMILLO URIBE, Jaime. (1982). El proceso de la educación en Colombia, del virreinato a la época contemporánea. En: Manual de Historia de Colombia, tomo III. Instituto Colombiano de Cultura. Bogotá.

MINISTERIO DE INSTRUCCIÓN PÚBLICA. (1911). Código de instrucción pública de Colombia. Bogotá, Imprenta Nacional de Colombia.

POMBO, Miguel Angel Y GUERRA, José Joaquín. (1951). Constituciones de Colombia. Tomo IV, Biblioteca Popular de Cultura Colombiana/Prensas del Ministerio de Educación Nacional. Bogotá.

SABATO, Hilda -Compiladora-.(1999). Ciudadanía política y la formación de las naciones. Perspectivas históricas de América Latina. El Colegio de México/ Fondo de Cultura Económica. México.

SÁENZ OBREGÓN, Javier; SALDARRIAGA, Oscar; Y OSPINA, Armando. (1997). Mirar la infancia: pedagogía, moral y modernidad en Colombia, 1903-1946. Tomo

Palubra No. 9 Agosto/2008 
I. Ediciones Foro por Colombia/Uniandes/Universidad de Antioquia. Bogotá.

URUETA, José P. (1912). Cartagena y sus cercanías, guía descriptiva de la capital del estado soberano de Bolívar, en los Estados Unidos de Colombia. Tipografía de Vapor Mogollón. Cartagena.

\section{BIOGRAFÍA}

Historiador (Universidad de Cartagena). Candidato a Magíster en Historia de la Universidad Nacional de Colombia (Sede Bogotá). Miembro del grupo de investigación Sociedad, Frontera y Región de la Universidad de Cartagena y del Grupo de Investigación Prácticas, Representaciones e Imaginarios de la Universidad nacional de Colombia. Miembro de la Red de Investigaciones en Estudios de Fiestas (RIEF) del Instituto de Estudios en Comunicación y Cultura (IECO) de la Universidad Nacional de Colombia. Profesor catedrático de los Programas de Historia y Trabajo Social de la Universidad de Cartagena. Email: rafacep@ hotmail.com/reacevedop@unal.edu.co.

\section{NOTAS AL PIE}

${ }^{1}$ GUERRA, FRANCOIS-XAVIER (1999). "El soberano y su reino. Reflexiones sobre la génesis del ciudadano en América Latina”. En: HILDA SABATO (Compiladora). Ciudadanía política y la formación de las naciones. Perspectivas históricas de América Latina. México, El Colegio de México/ Fondo de Cultura Económica, pág. 33.

${ }^{2}$ HERRERA, MARTA (2003). La identidad nacional en los textos escolares de ciencias Sociales. Colombia 1900-1950. Bogotá, Universidad Pedagógica Nacional, 382pp.

${ }^{3}$ DE LA VEGA, FERNANDO (1946). "La constitución del 86. Su proceso íntimo". En: Boletín historial. Órgano de la academia de Cartagena de Indias. Cartagena, Academia de Historia de Cartagena, pág. 14.

${ }^{4}$ Ver en este sentido el artículo de: HERRERA, MARTA (2001). "Debates sobre raza, nación y educación: chacia la construcción de un $<<$ hombre nacional $>>$ ?". En: MARTA HERRERA Y CARLOS JILMAR DÍAZ (Compiladores). Educación y cultura política: una mirada multidisciplinaria. Bogotá, Universidad Pedagógica Nacional, págs.117-142.

${ }^{5}$ POMBO, MIGUEL ANGEL Y GUERRA, JOSÉ JOAQUÍN (1951). Constituciones de Colombia. Bogotá, Tomo IV, Biblioteca Popular de Cultura Colombiana/Prensas del Ministerio de Educación Nacional, págs. 210, 219 y 326.

${ }^{6}$ SÁENZ OBREGÓN, JAVIER; SALDARRIAGA, OSCAR; Y OSPINA, ARMANDO (1997). Mirar la infancia: pedagogía, moral y modernidad en Colombia, 1903-1946. Tomo I. Bogotá, Ediciones Foro por Colombia/Uniandes/Universidad de Antioquia, págs. 249-258.

${ }^{7}$ GUERRA, FRNACOIS-XAVIER (1999), pág.33.

${ }^{8}$ SABATO, HILDA (1999). Ciudadanía política y la formación de las naciones. Perspectivas históricas de América Latina, pp. 11-29. FONTANA, JOSEPH (2003). "Estado, nación e identidad en América Latina". En: ¿Para qué sirve la historia en un tiempo de crisis? Bogotá, Ediciones Pensamiento Crítico / Colección Mundo sin Fronteras, pág.172-194. CARMAGNANI, MARCELO (2004). El Otro Occidente. América Latina desde la invasión hasta la globalización. México, El Colegio de México / Fondo de Cultura Económica, pág. 261-268. 
${ }^{9}$ SOLANO, SERGIO (2004). "Política e Intelectuales en el Caribe Colombiano durante la regeneración: 1886-1899". En: IV seminario internacional de estudios del Caribe. Memorias. Barranquilla, Fondo de Publicaciones Universidad del Atlántico/ Instituto Internacional de Estudios del CaribeUniversidad de Cartagena, págs. 169-172. BRAVO, IVONE (1998).Comportamientos ilícitos y mecanismos de control social en el Bolívar grande. Cartagena, Premio Departamental de Cultura/ Ministerio de Cultura, págs. 28 - 29 y siguientes.

${ }^{10}$ Sobre la Instrucción Publica en la Provincia de Cartagena: URUETA, JOSÉ P. (1912). Cartagena y sus cercanías, guía descriptiva de la capital del estado soberano de Bolívar, en los Estados Unidos de Colombia. Cartagena, Tipografía de Vapor Mogollón, Págs.232-300. Nota: esta segunda edición fue corregida por Eduardo G. de Piñeres.

${ }^{11}$ GRAHAM, RICHARD (1999). "Ciudadanía y jerarquía en el Brasil esclavista". En: HILDA SABATO (Compiladora). Ciudadanía política y la formación de las naciones. Perspectivas históricas de América Latina; p.346. BENDIX, REINHARD (1980). Estado Nacional y Ciudadanía. Buenos Aires, Amorrortu Editores, 285PP. FURET, FRANCOIS (1980). Pensar la revolución francesa. Madrid, Ediciones Petrel, 255pp.

${ }^{12}$ Entre tales derechos se contaban con, primero, los derechos civiles tales como la libertad de la persona, la libertad de palabra, de pensamiento y de fe, el derecho a la propiedad personal y a establecer contratos validos, y el derecho a la justicia. Segundo, los derechos políticos, como el sufragio y el derecho a ocupar cargos públicos. Y tercero, los derechos sociales, que van desde el derecho a un mínimo bienestar y seguridad económica hasta el derecho a compartir plenamente el patrimonio social y a vivir como un ser civilizado. BENDIX, REINHARD (1980); pág. 80.

${ }^{13}$ BENDIX, REINHARD (1980); pág. 80.

${ }^{14}$ CARMANANI, MARCELO Y HERNÁNDEZ, ALICIA (1999). "La ciudadanía orgánica mexicana, 1850- 1910". En: HILDA SABATO (Compiladora). Ciudadanía política y la formación de las naciones. Perspectivas históricas de América Latina; págs. 371 - 404.

${ }^{15} \mathrm{Al}$ respecto ver: ANINO, ANTONIO (1999). "Ciudadanía versus gobernabilidad republicana en México. Los orígenes de un dilema". En: HILDA SABATO; pág. 63 y siguientes.

${ }^{16}$ En ese sentido nos apoyaremos en las reflexiones de: Herrera, Marta (2003); pág. 58 y siguientes.

${ }^{17}$ HOBABAWM, ERIC J. (2001). En: Historia Social. Bogotá, Edición Número 40, pág.203. Este articulo es una traducción al español de la introducción del texto de: HOBABAWM, ERIC y TERENCE, RANGER (983). The invention of tradition. Norteamérica, Cambridge University Press.

${ }^{18}$ La ciudadanía política la entenderemos como una invención política predestinada a la imaginación y representación de un sentido de nación compartido, ese sentido está adscrito a una religión, una lengua, un pasado y unos valores nacionales en común. Sobre el carácter imaginado de la ciudadanía recomendamos el sugestivo trabajo de: ESCALANTE, FERNANDO (1993). Ciudadanos Imaginarios. México, El Colegio de México, págs. 18 y SS.

${ }^{19}$ Biblioteca Nacional de Colombia (en adelante B.N.C.) B.N.C. "Federalismo en la costa" y "Los problemas de la costa. Los peligros separatistas". En: El porvenir. Cartagena, 14 de enero de 1911, p. 2; "Hacia la federación". En: El porvenir. Cartagena, 8 de febrero de 1911, pág. 2; "Que hay de Panamá". En: El porvenir. Cartagena, 9 de abril de 1911, pág. 2.

${ }^{20}$ MINISTERIO DE INSTRUCCIÓN PÚBLICA (1911). Código de instrucción pública de Colombia. Bogotá, Imprenta Nacional de Colombia, págs. 23-25.

${ }^{21}$ MINISTERIO DE INSTRUCCIÓN PÚBLICA (1911); pp.22-23. Ver también el concordato de 1887: JARAMILLO URIBE, JAIME (1982). "El proceso de la educación en Colombia, del virreinato a la época contemporánea". En: Manual de Historia de Colombia, tomo III. Bogotá, Instituto Colombiano de Cultura, p. 279. Biblioteca Nacional de Colombia (en adelante B.N.C.) "Algo sobre 
educación en Colombia”. En: El porvenir. Cartagena, enero 7 de 1903, Pág. 2.

${ }^{22}$ MINISTERIO DE INSTRUCCIÓN PÚBLICA (1911); p. 23. Igualmente ver en la Biblioteca Luís Ángel Arango (en adelante BLAA) -sesión libros raros y manuscritos- : Acosta de Samper, Soledad (1896).Domingos de la familia cristiana: evangelios, prácticas y conversaciones sobre religión. Paris, Garnier, 336pp. Sobre el caso específico de Cartagena: Archivo Eclesiástico de Cartagena. "Carta Eclesiástica de su Santidad Pío X". En: Pastoral colectiva, Documento oficial, No. 76. Cartagena, Tipografía Pontificia de San José, 1905, pág. 28.

${ }^{23}$ MINISTERIO DE INSTRUCCIÓN PÚBLICA (1911); pág.23.

${ }^{24}$ TOVAR ZAMBRANO, BERNARDO (1997). "Porque los muertos mandan. El imaginario patriótico de la historia colombiana". En: Carlos Miguel Ortiz Sarmiento y Bernardo Tovar Zambrano (Compiladores) Pensar el pasado. Bogotá, Archivo General de la Nación / Universidad Nacional de Colombia, pág. 143 y 160.

${ }^{25}$ MINISTERIO DE INSTRUCCIÓN PÚBLICA (1911); pág.23.

${ }^{26}$ B.N.C. "Algo sobre educación en Colombia". En: El Porvenir. Cartagena, enero 7 de 1903, pág.2

${ }^{27}$ B.N.C. "Ley 39 de 1903 sobre instrucción pública". En: Registro de Bolívar. Cartagena, 22 de diciembre de 1903, pág.505 y 506.

${ }^{28}$ B.N.C. Gaceta Departamental de Bolívar. Cartagena, $1^{\circ}$ de mayo de 1912, pág. 435; Gaceta Departamental de Bolívar. Cartagena, 12 de abril de 1913.

${ }^{29}$ Sobre la formación de la clase obrera y sus sitios de trabajo: SOLANO, SERGIO (2001). "Formación de los trabajadores Fabriles en el Caribe Colombiano". En: El Taller de la Historia, No. 1. Cartagena, Facultad de Ciencias Humanas /Programa de Historia /Universidad de Cartagena, pág. 83 y siguientes. SOLANO, SERGIO (2003).Puerto, sociedad y conflicto en el Caribe colombiano, 1850-1930. Cartagena, Observatorio del Caribe Colombiano/ Ministerio de Cultura / Universidad de Cartagena, pág. 70-79. Archivo Histórico de Cartagena. "Cuadro demostrativo de la matricula y el movimiento de las escuela nocturna en el mes de 1908". En: Sección Gobernación (manuscritos) fondo de educación. Cartagena, Tomo 19, febrero 4 de 1918.

${ }^{30}$ MINISTERIO DE INSTRUCCIÓN PÚBLICA (1911); pág. 24.

${ }^{31}$ B.N.C. Academia Nacional de la Historia. "Apertura de concursos de temas históricos", "concurso para textos de historia de Colombia", "preparación del centenario de la independencia". En: Boletín de historia y antigüedades. Órgano de la Academia de Historia Nacional Año III-No. 25. Bogotá, Academia Nacional de la Historia, 1905, págs. 59-62.

${ }^{32}$ Asi, por ejemplo, en una comunicación a los maestros, el Inspector Escolar, Antonio García, en su afán por mostrar un cuadro en el que parecían los nueve próceres fusilados por Pablo Morillo, el 24 de febrero de 1816, resumía el significado patriótico de ellos, diciendo la siguiente filosofía educativa que debía enseñarse en las escuelas: “(...) nada tan propio para hacer revivir en el corazón de los colombianos el amor a la gloria, al heroísmo, y, llegado el caso, al sacrificio por la Patria, como el sublime ejemplo de los eximios próceres y mártires Ayos, Amador, Aguiano, Castillo, y Rada, García de Toledo, Granados, Portocarrero, Ribón y Stuard, que llevaron al cadalso encendida en sus corazones, la antorcha que debía iluminar para siempre el cielo de la Libertad en el mundo de Colón". García, Antonio. "A los maestros". En: Urueta, José P. Los mártires de Cartagena: Lección objetiva de historia patria. Popayán, Imprenta del Departamento, 1912, pág.1. El subrayado es del original. Las negrillas son de original.

${ }^{33}$ MINISTERIO DE INSTRUCCIÓN PÚBLICA (1911); pág.24.

${ }^{34}$ MiNiSTERIO DE INSTRUCCIÓN PÚBLICA (1911); pág.24. Del mismo modo ver: B.N.C. "Ordenanza sobre la enseñanza de la historia de la independencia en las escuelas públicas del departamento". En: Gaceta Departamental de Bolívar. Cartagena, 24 de Mayo de 1911, pág.224. De igual manera, en el decreto número 946 de 1910, se establecía que "del 1º de enero de 1911 
en adelante las clases de historia y geografía patria en todos los establecimientos de instrucción pública, estarán a cargo de profesores colombianos". Ver al respecto: Gaceta Departamental de Bolívar. Cartagena, 3 de Diciembre de 1910, pág.156.

${ }^{35}$ MUNERA, ALFONSO (2005). Fronteras imaginadas. La construcción de las razas y de la geografía en el siglo XIX colombiano. Bogotá, Editorial Planeta, págs. 175-178.

${ }^{36}$ MINISTERIO DE INSTRUCCIÓN PÚBLICA (1911); pág. 25.

${ }^{37}$ B.N.C. Fernández Baena, Alberto E. Colegio Fernández Baena Fundado en 1933. Cartagena, Tipografía Mogollón, 1934, pág. 14. Las negrillas son del original.

${ }^{38}$ ARRUBLA, GERARDO Y HENAO, JESÚS MARÍA (1911). Compendio de la historia de Colombia para la enseñanza en las escuelas primarias de la República. Bogotá, Imprenta Eléctrica, pág. 188.

${ }^{39}$ DÁVILA FLOREZ, MANUEL (1903). Código de policía del departamento de Bolívar con las modificaciones introducidas por las ordenanzas posteriores á la 54 de 1892 : concordado consigo mismo, con la constitución y con los código civil, penal, de organización judicial, político y municipal y judicial, con comentarios y un prefacio sobre policía y sobre las reformas que convendría introducir en el mismo código. Cartagena, Tipografía de Vapor de Araujo L., págs. 209-213. De igual manera ver: CALVO, RAFAEL (1925). Código de policía del departamento de Bolívar. Cartagena, Ed. Departamental, págs. 93-95.

${ }^{40}$ BRAVO, IVONE (1998); pág. 28.

${ }^{41}$ CALVO, RAFAEL (1930) Código de policía del Departamento de Bolívar. Cartagena, Imprenta Departamental, pág.111.

${ }^{42}$ La "suciesa moral" fue el termino más utilizado para cuestionar el carácter de "holgazanes" y "vagos" de algunos estudiantes en la ciudad de Cartagena. Sobre este concepto ver: B.N.C. El porvenir. Cartagena. 16 de Marzo de 1911, pág.3.

${ }^{43}$ Ahora bien, no sólo el concepto de ciudadanía encontraba su adverso en los códigos de policía y las practicas consideradas ilegitimas por parte del Estado colombiano. Ya que, de igual manera, la construcción de la categoría de nación se hacía excluyendo y deslegitimando a los grupos renuentes a la concepción filosófica del país. Sobre estos sentidos de la elaboración conceptual de la nación ver: SERGE, MARGARITA (2005). El revés de la nación: territorios salvajes, fronteras y tierras de nadie. Bogotá, Universidad de los Andes, Facultad de Ciencias Sociales (CESO), 295pp.

${ }^{44}$ CALVO, RAFAEL (1930); págs. 112.

${ }^{45}$ B.N.C. El Porvenir. Cartagena, 16 de Marzo de 1911, pág.3. Las negrillas son el original.

${ }^{46}$ CALVO, RAFAEL (1930); pág.115.

${ }^{47}$ CALVO, RAFAEL (1930); pág. 111.

${ }^{48}$ BUENAHORA, GIOVANNA (2001). "La educación pública femenina en Cartagena, 1870 - 1900". En: Desorden en la plaza. Cartagena, Instituto Distrital de Cultura, pág. 49 y siguientes.

${ }^{49}$ BADINTER, ELIZABETH (2000). XY, La Identidad Masculina. Bogotá, Norma, pág. 19 y siguientes.

${ }^{50}$ B.N.C. Gacela Departamental de Bolívar. Cartagena, 12 de abril de 1913, pág.2504

${ }^{51}$ DÁVILA FLOREZ, MANUEL (1903); págs. 218-219.

${ }^{52}$ CALVO, RAFAEL (1930); págs. 115-118. 